\title{
Action of galvanic current on an experimentally generated muscle lesion: preliminary findings
}

\author{
Santafe M.M. ${ }^{1}$ Margalef R. ${ }^{1}$ Minaya Muñoz F. ${ }^{2}$ Valera Garrido F. ${ }^{2}$ \\ 1 Unit of Histology and Neurobiology, Department of Basic Medical \\ Sciences, Faculty of Medicine and Health Sciences, Rovira i Virgili \\ University, Reus, Spain \\ 2 Physiotherapy Service MVClinic. Pozuelo de Alarcón, Madrid, Spain \\ Rev Fisioter Invasiva 2019;2:108-109.
}

\begin{abstract}
\section{Keywords}

- galvanic currents

- percutaneous needle electrolysis

- mouse

- partial muscle lesion

Background Recently, Abat et al evaluated the effect of the application of galvanic currents on a model of muscle injury in the rat by injection of intramuscular Notexin. In mice, Notexin causes a lesion of the entire muscle when in humans, complete affectation is exceptional. In this study, we evaluated the action of the galvanic current on muscle regeneration in partially lesioned muscles with bupivacaine.

Aim To evaluate the action of the galvanic current in an animal model with partial muscle lesion generated with Bupivacaine.

Material and Methods The experiments were performed in adult male Swiss mice who were intramuscularly inoculated with Bupivacaine (BPV) in the posterior muscle bundle of the leg. The control subjects were inoculated with physiological saline (PS). The galvanic current protocol used in this study was $1.5 \mathrm{~mA}$ during 5 seconds and 3 applications (1.5:5:3; Physio Invasiva ${ }^{\circledR}$, Grupo Prim). The electromyographic recording was performed at 72 hours and at 7 and 10 days, after the first administration (Medelec Synergy Ultrasound machine, concentric recording needle). The number of areas presenting endplate noise were evaluated and the frequency of endplate noise for each of these areas.

Results Considering that the fibers which have been lesioned by bupivacaine are electromyographically silent, a registration of endplate noise was related with muscle regeneration. The number of areas with endplate noise considerably increased in the injured limb which received the galvanic current compared to the limb that was only lesioned in the first 72 hours. After this, there was no other modification in the number of areas. The frequency of the endplate noise of each area has been significantly greater in all the periods studied, indicating that galvanic current has facilitated muscle regeneration. It is worth noting that these are preliminary results and other more direct tests are pending.

Conclusions The functional findings uncovered in this study, enable us to establish that the application of galvanic currents in an animal model of muscle injury reduce the recovery time of the damaged muscle tissue.
\end{abstract}

DOI https://doi.org/ $10.1055 / \mathrm{s}-0039-3401881$ ISSN 2386-4591.
Copyright @ 2019 by Thieme Revinter

Publicações Ltda, Rio de Janeiro, Brazil
License terms

$\circledast(1) \Theta \circledast$ 


\section{Acknowledgments}

The authors wish to thank the PRIM Physiotherapy company who have selflessly provided needles and the Physio Invasiva ${ }^{\circledR}$ device used in this study to generate galvanic currents. This research is partially funded by a grant by Instituto de Salud Carlos III, Acción Estratégica en Salud (MMS, PI13 / 02084). 